\title{
Otras músicas
}

\author{
CARLOS PEREDA \\ Universidad Nacional Autónoma de México
}

No, un poema no es un acto de comunicación. Si se busca comunicar importa el mensaje, y cuanto más eficaz sea su transmisión, mejor será el proceso de comunicación. De ahí que cuando nos expresamos de manera exitosa con palabras, el lenguaje no interviene, no distrae, se adelgaza hasta la transparencia, incluso desaparece y deja paso de manera directa a ciertos contenidos: esa, al menos, debe ser la experiencia de su receptor. Si en una situación habitual se dice:

por favor, cierra la puerta,

se usan algunas palabras para pedir una acción. Sin embargo, esas palabras no se recortan de su contexto, por así decirlo, no se presentan a sí mismas escritas con tinta colorada: son invisibles y se borran delrás de los conceptos que realizan tal pedido. Por eso, en casi cualquier situación, en la práctíca resultarfa lo mismo decir:

hazme el favor de cerrar la puerta te ruego que cierres la puerta ¿podrías cerrar la puerta? Gracias

Por otra parte, si no se entiende alguna de esas expresiones y se pregunta, no se pregunta por las palabras en tanto palabras, en tanto texto, sino por su sentido, por aquello a que refieren, por su tiso en esa situacion. Es una convención frecuentada entrecomillar las palabras para ocuparse con ellas; como se dice en lógica, se mencionan las palabras... para inclinarse sobre su superficie, para atenderlas mejor. Así, si se tienen dificultades con la orden (pedido...) de cerrar la puerta, tal vez se interrogue:

¿qué quieres dccir con la expresión aclena la puertas?

¿a qué puerta te refieres con la expresión «cierra la puerta»?

En casos como estos, cuando no se entiende $y$, por eso, los contenidos que se procuran transmitir no llegan al receptor, se produce un «bloqueon en la comunicación. Frente a cualquiera de estos bloqueos es del mayor interés lo que tiene que decir al respecto el emisor del mensaje: quizá se expresó de manera confusa, tal vez no encontró las palabras más adecuadas..., de cualquier manera, «lo que quiso decir" el cmisor es decisivo en relación con «lo que dijon, y asi, quien habla o escribe podra matizar, corregir, modificar... lo ya expresado; la primera persona, pese a todos sus tropiezos, conserva la última palabra en relación con "lo que dijo». Además, las «interpretaciones" que levantan tales bloqueos son verdaderas o falsas, verdad o falsedad que se evaluará contrastando alo que se quiso decir" con "lo que se dijo" tan ineptamente que ha bloqueado la comunicación. Pero... ¿qué entiendo, en general, con la reiterada expresión «bloqueo de la comunicación"?

Bloquear es cercar, sitiar: se bloquea una ciudad o un puerto enemigo para evitar que se entre a esa ciudad, a ese puerto o se salga de ellos. Bloquear una comunicacion es interrumpirla en algún sentido, dejarla en suspenso, con 
la expectativa de que algo tiene que continuar (¿el mensaje detenido?) aunque... Interrumpir a menudo nos excita, según la circunstancia, de la peor manera, o de la mejor manera.

Sin embargo, hay muchos modos de interrumpir una comunicación. Bloquearla de manera interna es molestarla desde dentro, poner un tope en medio de la transmisión del mensaje. Por ejemplo, cuando se arruina un pedido porque, tontamente, no se entienden palabras como "cierra la puerta", estamos ante un bloqueo interno accidental en la comunicación. En el límite, en cambio, la confusión puede ramificarse hasta que se apodera de toda una perspectiva de comprensión: si para nada se entiende una cultura, o peor, si una dimensión decisiva de ciertas vidas, como la experiencia religiosa, resulta un enigma del que hay que rápidamente deshacerse, se producen blaqueos internos sistemáticos de la comunicación.

Cuidado; al empezar a leer un poema hay que dejar de lado todo este vocabulario. Sír el lector de poesía tiene que olvidarse de expresiones como "comunicacion", "mensaje transmitido", "bloqueos internos accidentales", «bloqueos internos sistemáticos"... porque nada de ello sucede cuando se lee un poema. ¿Cómo es esto?

En primer lugar, un poema elimina la oposición uso/mención de las palabras en tanto oposición: un poema usa el lenguaje - sus sentidos, sus referencias- $y$, a la vez, menciona el lenguaje que usa, pide contemplarlo, casi diria, acariciarlo palmo a palmo. Para nombrar a este doble operar, a este usar y mencionar simultáneos, diré que en un poema las palabras se wexhiben"; exhibir es lucir, mostrar algo con orgullo, llamar la atención, alardear, ostentar.... en cualquier caso, un exceso. En relación con la poesia debe introducirse, entonces, un postulado de la exhibición de las palabras, del uso y lucimiento palabrero.

O si se prefiere expresar este postulado desde el punto de vista del lector, abusando de una metáfora marina podría indicarse que, al leer un poema, el lector se encuentra con "marea textuals: el lector se dejara llevar, se tendrá que dejar llevar por las palabras, de aquí para allá... Tal vez a ello aluda - ¿paradojalmente? - el culto de Flaubert al mot juste. $\mathrm{Y}$ búsquedas análogas se encuentran por doquier: porque no hay poesía sin que la ostentación de sus palabras produzca dicha umareas.

En segundo lugar, este elaborado alarde no configura un bloqueo en la comunicación, sino de la comunicación. Pues un poema no levanta un bloqueo interno sino externo: se intercepta la comunicación, se la detiene, pero no desde dentro de ella, por algún enredo accidental o sistemático, sino desde fuera, por la constitución misma del extraño objeto con que se topa, ese conjunto admirable o atroz de palabras que conforman el texto del poema.

Los bloqueos internos, accidentales o sistemáticos, son fallas de la comunicación. En cambio, los bloqueos externos son sus provocaciones: por eso, un poema no simplemente corta la comunicación, sino que esa interferencia... desenvaina una espada. Este ostentar desmesurado, esta exhibición desordenadora de palabras que bloquea la comunicación con "marea textual», para un lector de poemas, al desafiar, separa al poema de cualquier otra práctica discursiva. "Apartarse provocando": para caracterizar a este segundo operar, según el poema que se esté leyendo, pueden usarse varias expresiones: un poema pone entre paréntesis las otras prácticas y discursos, produce 
una subversión de ellos, se rie, los critica, los condena, los desafia, los elogia, los realza, simplemente nos los recuerda..., en cualquier caso, un poema trata al resto de las prácticas y los discursos del mundo como lo otro que, en algún sentido, se le enfrenta y, a la vez, se caracteriza a sf mismo como ese espejo, o más bien, ese reflector que ilumina todo el resto, o al menos, un fragmento de ese resto o postulado del carácter definitivamente otro de la poesta.

De ahí que, para el lector, este segundo postulado areflector" opere como una "máxima de la imaginación centrífugan, como una invitación a que se explore en las más diversas direcciones teniendo como base el texto del poema... No corramos y, además, ¿de qué estoy hablando?

Quiero decir: $i$ en qué enredos nos pierden las operaciones de «exhibir palabras" y de kapartarse provocando"? $\mathrm{Y}$ ¿por que dejarse cautivar con fervor, $y$ hasta responder al uso de tales operaciones, abandonándose a la "marea textual», a la imaginación centrífuga? ¿Adónde conducen estos dos postulados acerca de - ¿en general?- la poesía?

Busquemos una respuesta leyendo un poema del libro Mutaciones, I de Enrique Ficrro:

\section{LA ENTONCES MÚSICA}

La entonces música vigilia abierta contra la oscuridad supo. No sabe más. Por eso rasga, firme, la palabra, hoy. Pero qué pronto muere.

Demasiado claro no queda el "mensaje" que se quiere "transmitir". Más todavía, si el poema iLa entonces música» pretendiese comunicar algo -una orden, un pedido, una información, un ruego, una pregunta... - su condena no tendría posible apelacion: la ineptitud para usar con cierta determinación el vocabulario $\mathrm{y}$ con relativa soltura la gramática es, más que inquietante, escandalosa. Además, y a diferencia de lo que sucede con un mensaje inepto que pertenece al circuito de la comunicación, no es posible apelar a «lo que quiso decir" el emisor de este puñado de palabras pues "acudir a lo que se quiso decir", a las cintenciones del mensaje", no es una posibilidad de este tipo de textos. Más todavía, si el autor de un poema interviniese para guiar su lectura, cualquier lector podría en el límite rechazar esas intervenciones como malentendidos del propio autor, y en ningún caso se mantiene la autoridad de la primera persona, propia de la comunicacion. ¿Que hacer, pues?

"La entonces música", sin duda, ostentosamente exhibe ciertas palabras y, adcmás, en ese mismo movimiento de exhibición se separa y... ¿nos provoca? Pero ¿en qué sentido provoca? ¿y a qué nos provoca... o al menos, convo$\mathrm{ca}$ ?

Lo que suele llamarse "retórica», o más bien, y en su sentido más abarcador, "retóricas», han sido tradicionalmente las encargadas de "hacerse cargo", de "controlar" un poco estos alardeos insensatos, de "disciplinar" esa "marea textual" a que un poema condena a su lector. La retórica grecolatina, de Aristóteles a Quintiliano, fijó cinco operaciones a que el orador debía echar mano para construir sus discursos: inventio, dispositio, elocutio, actio y memoria. Esta lista de viejas palabras latinas es heterogénea, las tres primeras palabras indican condiciones internas de producción de discursos o textos, las dos últimas, condiciones ex- 
ternas; además, el orden es psicológico, o acaso, psicológico-didáctico, está pensado desde el punto de vista de quien construye discursos, $y$ en este momento, lo que nos interesan son guias de lectura, de re-construcción, no de producción de textos. En medio de las perplejidades - de la «marea textual"- en que nos encontramos, elijo - un poco al azar-, y sólo como punto de partida, atender la dispositio de "La entonces mutisica". Pero alerta: en ningún caso nos toparemos con "interpretaciones" verdaderas o falsas, sino con lecturas cuidadosas o torpes, iluminadoras o mezquinas, abredoras de caminos o empobrecedoras.

Hallamos en "La entonces música" una estructura simple: se exhibe un conjunto de palabras comunes que articulan dos escenas vinculadas por un nexo causal. La primera escena se organiza en torno a un texto en el cual cierto agente un tanto misterioso, o más bien, muy misterioso, "la entonces músican, está despierto y vcla y sabe contra la oscuridad - pero ¿de que oscuridad se trata? - versus un contratexto que informa que aquello ya no vale, pues el misterioso agente no sabe más. La segunda escena, la escena que según el nexo causal sucede a la primera, indica en el texto que la palabra - $i$ heredera de aquella música?- rasga -rompe, hace pedazos con fuerza...- hoy, versus un contratexto que, de inmediato, acota que el romper firme de esa palabra, y la palabra misma, lamentablemente, es fugaz, "pronto muere".

La elocutio del poema, sus figuras retóricas, reafirman esta primera aproximación. Pareciera que nos encontramos ante una alegoria en tanto "La cntonces músican se genera en la contraposición como momentos de una historia de dos prosopopeyas. El verso inicial articula la personificación que da título al poema, construyéndola con un enálage (el adverbio se usa como adjetivo), "La entonces música", y el segundo verso la califica con una metáfora que sugiere un estar despierto y con cuidado y atención de lo que está a su cargo, y claridades, vida, los vastos horizontes...: "vigilia abierta contra la oscuridads. En el tercer y cuarto verso dos acciones se le atribuyen a esta fuerza que es atalaya y luz: la música de antaño tuvo sabidurfa, pero ay, ya la ha perdido. La segunda personificación, la heredera de la fuerza de la música, "la palabra», se presenta en el sexto verso rodeada de elipsis: de la música de ayer sólo qucda rasgar, hacer pedazos, romper... ¿abrirse paso?: firme pero fugaz.

Por lo pronto, la reconstruccion de la dispositio y de la elocutio de "La entonces música" parecen confirmar, o al menos, ofrecer buenas razones para respaldar los postulados generales propuestos acerca de la poesfa: se han exhibido varias palabras y esa ostentación nos ha conducido a cierta "otredad» en algún sentido desafiante: una manera de atender radicalmente diferente. Sin embargo ¿en qué consiste este atender que provoca "La entonces música?", ¿cual es el contenido de ese rotar la atención? Esto es ¿qué materiales nos ofrecen las dimensiones reconstruidas de "La entonces música" para que nuestra imaginación centrifuga encuentre su inventio $o$, al menos, algunas de sus posibilidades?

Antes que nada, protesto: creo que seria un error pensar "La entonces músican a partir del Nietzsche de $E l$ nacimiento de la tragedia. Para ese Nietzsche, las llamadas uexcelencias" de la razón, de la palabra, las ciencias, las técnicas, la moral universal, la democracia, los cultos, pues, de Apolo, la «tradición socrátican, en verdad, no expresan más que disolución, deca- 
dencia, superficialidad, negación de la vida. Sólo la música de "lo dioniśacon, del instinto, puede salvarnos, puede reintegrarnos al "evangelio de la armonía universals: nos hace cantar y no hablar. Ahora bien, si no me equivoco, en "La entonces música" se evitan los vértigos simplificadores de Nietzsche, no se dramatizan las nostalgias de la música, del instinto, frente a la palabra, la razón. Más bien se nos desafía a percibir la herida de muerte alli donde se pose la mirada: por donde haya pasado el tiempo. Es el viejo descubrimiento - redescubierto por cada generación, y penosamente, y a menudo a los golpes, por cada persona- $y$, por eso, el viejo topos retórico de que nada permanece: fugacidad de lo que fue, de lo que es, de la palabra, pero también de la música... Sin embargo, el poema no se limita a recordar esas vagas generalidades. La música se exilia en la palabra, y la palabra cree confiada, por un momento, que es capaz de vencer, alli donde perecio la música:

\section{Por eso, rasga \\ firme, la palabra hoy.}

Y porque la palabra y la razón caminan más o menos juntas, e incluso tienden a entramarse, también quizá se podría traducir, o simplemente, continuar afirmando:

Por eso, rompe, y se abre paso a la fuerza, firme, la razón

hoy.

Creemos, o más bien, queremos creer que las excelencias de la razón no están heridas de muerte: son efirmes». Recuerdo las ya anotadas excelencias de la palabra, de la razón, las ciencias, las técnicas, la moral universal, la democracia: a tales excelencias existe una tendencia generalizada de atribuirles una consistencia, un estar en "firmen, que no poseen. Asl, un frecuente sobreentendido, y la esperanza que se disfraza de tal sobreentendido, su soberbia, es que tales excelencias duren, progresivamente, para siempre. Más todavía, deseamos pensar tales excelencias como si fuesen procesos perpetuum mobile: procesos infinitos y sin necesidad de energia exterior. Inevitablemente se trata de procesos precarios.

En contra de la arrogancia de la palabra, de la razón, que creen poder "rasgar firme», "La entonces música subraya, entonces, que, como la música, tampoco la palabra, o la razón, escapan a la incertidumbre, y acaso todavía más incierta la palabra, la razón: ello implica: más necesitadas de nuestros cuidados, de nuestra "vigilia abiertan día a día.

Seguramente ya se protestará, y hasta los insultos: "La entonces música» ofrece en algún sentido buenas razones para respaldar tanto el postulado de la exhibicion de las palabras, como el postulado del carácter definitivamente otro de la poesia, porque se trata de un texto muy particular, un poema que se incluye en la poética de las llamadas "vanguardias" del siglo $\mathrm{xX}$ (en la poética de alguna de las beneméritas "vanguardias"), poéticas que, precisamente, se generan, o al menos, suelen tener muy en cuenta ambos postulados. Incluso se podrá conceder que fuera de tales poéticas estos postulados también pueden recibir otros apoyos; para no ir más lejos y ofrecer ejemplos de la poesfa del Uruguay, la poesía que más inmediatamente enmarca -aunque en ningún sentido aprisiona a agota- la poesía de Fierro, hasta en tal tradición, digo, se encuentran con facilidad ilustraciones claras de ambos postulados, hacia atrás, poemas "modernistas" de Julio Herrera y Reissig como: 
En túmulo de oro vago, cataléptico fakir,

se dio el tramonto a dormir...

o hacia adelante, en la poesía, por llamarla de algún modo, "post-concreta" de Eduardo Milán:

Limpia tus palabras, limpia tus palabras, mira que por algo te lo digo. Ya veo que [por algo me lo dices: ¿es por el mirlo? Mirlo: me veo en el mirlo, se refiere a mí. ¿Puedo? Una [palabra sucia...

Más abarcadoramente, a la sombra de los nombres ya iconos de Góngora, Mallarme, Joyce..., y en las tradiciones que ellos inician $\mathrm{y}$, a veces, ponen en marcha, también habrá, y cómo, abundantes respaldos al «usar $y$, a la vez, mencionar palabras» y al «apartarse provocandon. No obstante, por ejemplo, en textos más tranquilamente descriptivos o confesionales y apasionados ¿acaso estos postulados no se descubren como fuera de lugar? Y si este es el caso, la generalidad de tales postulados ino se nos muestra como estrechamente prescriptiva o ilusoria?

Frente a protestas como éstas sólo se me ocurre seguir leyendo; probemos, pues, con un texto muy diferente a "La entonces música», de un poeta también muy diferente a Enrique Fierro, el poema, más largo $y$ aparentemente bien "realista", moroso, con detalles, "Chopin", de Gottfried Benn:

\section{CHOPIN}

Nicht sehr ergiebig in Gespräch Ansichten waren nicht seine Stärke, Ansichten reden drum herum, wenn Delacroix Theorien entwickelte, warde er untruhig, er seinerseits konnte die Nottumos nicht begrunden.

Schwacher Liebhaber;

Schatten in Nohant, wo George Sands Kinder

keine erzieherischen Ratschläge

von ihm annahmen.

Brustkrank in jener Form

mit Blutungen und Narbenbildung.

die sich lange hinzieht;

stiller Tod

im Gegensatz zu einem

mit Schmerzparoxysmen

oder durch Gewehrsalven:

man nickte den Fligel (Erard) an die Tür

und Delphine Potocka

sang ihm in der letzten Stunde

ein Veilchentied.

Nach England reiste er wit drei Flügeln:

Pleyel, Erard, Broadwood,

spielte für 20 Guineen abends

eine Viertelstunde

bei Rorhschilds, Wellingtons, in Strafford

[Hotse

und vor zahilosen Hosenbändern;

verdunkett von Müdigkett und Todesnähe

kehrte er heim

auf den Square d'Orleans.

Dann verbrennt er seine Skizzen

und Manuskripte,

nut keine Restbestände, Fragmente, Notizen,

- diese verräterischen Einblicke -,

sagte zum Schluss:

"meine Versuche sind nach massgabe

was mir za erreichen mögltch war."

[dessen vollender,

Spielen sollte jeder Finger

mit der seinem Bau entsprechenden Kraft,

der vierte ist der schwächste

(nur siamesisch zum Mittelfinger).

Wenn er begann, lagen sie

aufe, fis, gis, $h, c$.

Wer je bestimmte Präludien

von ithm horte,

sei es in Landhäusem oder

in einem Höhengetände

oder aus offenen Terrassentüren

beispielsweise aus einem Sanatorium.

wird es schwer vergessen.

Nie eine Oper komponiert,

keine Symphonie,

nut diese tragischen Progressionen

aus artistischer Überzeugung

und mit einer kleinen Hand. 
Traduzco a continuación el texto de Benn, no sin muchas vacilaciones $y$ dudas $(\mathrm{y}$, al menos, con una inevitable, creo, y precisa confusión):

\section{CHOPIN}

No muy fecundo en la conversación, las opiniones no eran su fuerte, las opiniones hablan dando vueltas, cuando Delacroix desarrollaba teorias, se ponia inquieto, él no podía justificar los Nocturnos.

Amante débil;

sombra en Nohant,

donde los niños de George Sand.

no le aceptaron

ningún consejo educativo.

Enfermo de los pulmones con sangrados y cicatrices, que se prolongan largamente;

muerte calma

en contraste con una muerte

con paroxismos de dolor

o por descargas de tiros:

empujan el piano (Erard) a la puerta

y Delphine Potocka

le cantó en la última hor

un lied de violetas.

Viajó con tres pianos a Inglaterra:

Pleyel, Erard, Broadwood.

tocaba en las noches por veinte guineas

un cuarto de hora

en la casa de los Rothschilds, los

[Wellingtons, en la Strafford House

y delante de numerosas ordenes de

[Jarretera;

oscurecido de cansancio y cercanfa de

[muerte

regresó a casa

en el Square d'Orléans.

Luego quemó sus esbozos

y manuscritos,

ningún resto, fragmento, noticia

-esas miradas traicioneras-,

dijo al final:

"mis intentos son perfectos,

según la medida de lo que pude logrars.
Cada dedo debía tocar

con la fuerza correspondiente a su

[conformación,

el cuarto es el más débil

(sólo depende del dedo medio).

Al empezar, estaban puestos

en mi, fa sostenido, sol sostenido, si, do.

Quien alguna vez escuchó sus Preludios,

en casas de campo o

en un paisaje montañoso

o desde las puertas abiertas de una terraza

por ejemplo, en un sanatorio.

difícilmente lo olvidará.

Nunca compuso una ópera,

tampoco una sinfonía,

sólo esas progresiones trágicas

por convicción artística,

y con una mano pequeña.

¿Valen también para este "comunicativon poema, esas aparatosas rarezas, los dos postulados propuestos? Un lector distraído seguramente respondera con la negativa: el "Chopin" de Benn es un acto relativamente exitoso de comunicación, a saber, se transmite un mensaje más o menos preciso, se expone cierta biografía, al menos, se nos ofrecen algunos fragmentos biográficos en un informe relativamente impersonal. Yo discrepo y quiero poner en duda tal dictamen.

De nuevo, subrayo: si lo que procura este poema es comunicar una biografia de Chopin, o algunos fragmentos de ella, la condena es inapelable: para qué nos sirve una biografía que no señala ni dias ni meses ni años ni siglos, que ni siquiera indica cuándo nació, cuándo murió Chopin, que además, apenas alude vagamente a dos de sus obras y, en cambio, se demora en detalles tan minúsculos como los nombres de los pianos que poseía - ¿que poseía? - y con los que viajaba en sus giras... Insisto: si el proposito de este poema era informar algunos datos sobre la vida de Chopin, la entrada de la más humilde e inepta enciclopedia po- 
dría sustituirlo con ventaja. Entonces ¿de qué se trata?

Por lo pronto - primer postulado-. el "Chopin" de Benn exhibe ciertas palabras, digamos, su elocutio se hace con una serie de enunciados descriptivos, rotundos $y$, de vez en cuando algunas relativamente leves metaforas, eso de que "Ansichten reden drum herum" («las opiniones hablan dando vueltas") o "verdunkelt von Müdigkeit und Todesnahe" ("oscurecido de cansancio y cercanía de muerten),..., aunque el poema, en alto grado, adopta lo que suele llamarse un "tono sobrio". Sin embargo, esa sobriedad resulta un tanto descolocada - isegundo postulado? - porque se modula de manera impropia: como ya se adelantó, se habla en exceso de lo que no parece tener ninguna importancia (los nombres de los pianos con los que viajaba, los nombres de los dueños de algunas de las casas donde ofreció recitales, minucias sobre los dedos de la mano...).

Dejémonos llevar un poco por la "marca textual" de su dispositio. Las tres primeras estrofas articulan las penurias de Chopin; se comienza enunciando fallas en relación con la palabra: indigencia en la conversación, en el teorizar, en su capacidad educativa... pero el poema no se limita a ello, agrega, casi diría, martillea, también su debilidad erotica, su mala salud, el poema incluso casi regaña a Chopin por haberse privado de una muerte "importante", "espectacular" (¿Chopin se desliza hacia la muerte como un casi muerto?), miserias que podríamos considerar como el texto del poema. (Extrañamente, los poetas se han ensañado con estas carencias:

$$
\text { perfeccionista, mezquino y cuidadoso. }
$$

lo califica de manera despiadada una linea de Alberto Girri en su problemá- tico "Chopin como pedante». Y en un poema del "Mausoleo" de Hans Magnus Enzensberger, un texto armado con los sarcasmos y el vocabulario aprendidos en la escuela de Benn, y también, en la de Brecht, esto es, un retrato hecho con los hábitos de la tradición anti-Rilke de la poesía alemana, se describe a F.C. (1810-1849) como:

\section{Minutiöter Arbeiter. Legitimist, Dandy.}

Minucioso. Legitimista. Dandy.

Para concluir, $\measuredangle \sin$ espesor?, ¿ $\sin \mathrm{ge}-$ nerosidad?, ¿sin grandeza?, en cualquier caso, condenando:

... Uber ein schlechtes Gewissen verfigte er nicht. Seine linke Hand war gut. Die Unerbittlichkeit, mit der er, Zeit seines

für das Obberflüssigste eintrat, ist schwens, schwer zu Ierklären.

... No disponía de mala conciencia. Tenía buena mano [izquierda. La inflexibilidad con que toda su vida luchó por lo más superfluo, cuesta mucho de

[explicat:

Regresemos al texto de Benn. La cuarta estrofa funciona a la manera de una ligera transición: por un lado, se nos narra acerca de aparatosas giras de concierto, por otro, regresan las miserias de esta "alma en pena", sitiada ya por la muerte.

El escenario cambia radicalmente en la quinta y sexta estrofa que generan el contratexto del poema: el "hombre sin atributos", o sin más atributos que sus carencias, deja paso a un músico ansioso de quemar los caminos por donde ha buscado, de no dejar cabos sueltos en su obra, de borrar cualquier huella "traicionera», obsesionado por minucias como la de ocupar todos los dedas de la mano, y algo más. La cita de Chopin puede interpretarse, entre 
otras, de dos maneras: como quien se resigna en el sentido de "hice lo que pude" o "más no tenía con quén, o como quien acepta con un dejo de orgullo - ipero de orgullo herido?-, en el sentido de: "mis intentos, dentro de los límites de lo que podía hacer, se encuentran acabados" (vollendet), o hasta sugiriendo: "por favor, señoras y señores, por lo menos, he hecho todo lo que pude hacer, cosa nada corrientew. Si nos inclinamos por esta última interpretación, ello conduce a no reconocer para ciertos trabajos otro patrón que la "medida" inmanente. Así, en esta lectura, Chopin no habría aceptado otros modelos que los internos: habria rechazado cualquier juicio exterior a la propia obra.

Hasta aquí el informe. De pronto, en la séptima estrofa aparece el informante que recuerda y nos recuerda: quien en lugares apartados, en lugares solitarios, de retiro, alejados de la comunicación entre las gentes (una casa de campo, un paisaje montañoso, la terraza de un sanatorio...) haya oido ciertos Preludios de este "pobre hombre»... -pero "preludiosn a ninguna obraes seguro que su memoria, su "razón anamnstica", "dificilmente lo olvidará»: porque habrá sido utocado", y para toda la vida, por esas «progresiones trágicas» (iligerísimo oxímoron?), esas pequefias notas que caen, que caen, que vuelven a caer como gotas de lluvia antes del chaparrón.

Por otra parte, obsérvese que los tres últimos versos, en algún sentido, resumen el poema, enfatizando esas músicas que ejecuta una "mano pequeña» $y$ también, lo que podríamos llamar las "convicciones pequeñas", las convicciones técnicas del arte, o si se prefiere, sus juegos, sus astucias, sus oropeles, sus "marometas». En efecto, al traducir aus artistischer Überzeugung con la expresion "por convicción artística» introduje confusión en el verso de Benn; ¿cómo no hacerlo?, ya que el alemán díspone de dos voces para una sola palabra castellana; el equivalente alemán de la palabra castellana uartístico» es künstlerisch, digamos, Fierro y Benn son Künstler, en cambio, con la palabra artistisch el alemán refiere a otro tipo de aartistan, a los artistas de un circo o en general, a los artistas de cualquier show. Mano pequeña y convicciones pequeñas, ahora comprendemos la estrofa esa de que acada dedo debía tocar / con la fuerza correspondiente....s: ocuparse con lo pequeño, con lo bien hecho, sólo nos queda cllo, la técnica, en este caso, la técnica pianística y el trabajo minucioso, el trabajo en las pequeñas cosas de la vida (la transpiration, diría Wordsworth, no la inspiration).

Apliquemos todavía nuestra imaginación centrifuga a la inventio del poema "Chopin*. Una lectura apresurada encuentra ya el viejo topos retorico de la oposición entre la vida -en este caso, la epobre vida" - y el arte, o más bien, la desproporción entre la "pobre vida» de un "hombre sin atributos» $y$ el efecto, sin la menor proporcion con respecto a esa "pobre causa", su música, dificilmente olvidable. ¿Consiste, entonces, el capartarse provocador» del poema en invitarnos a pensar en esta falta de proporción entre lo que se es y lo que se puede hacer, o más bien, se puede ser? Sospecho que no es la única des-proporción con que se nos desafía. El solitario habitante de una casa de campo, el caminante no menos solitario de un paisaje montañoso $y$, sobre todo, quien se encuentra en la soledad de la terraza de una scasa de enfermos», al oír esas "trágicas progresiones» convocará a sus soledades los reflejos de otra experiencia, será «tocado" por otra cxperiencia: los "prólogos a nadan que recuerdan la precariedad de todos los procesos de nuestra vida 
como lo único que permanece y que, aunque no nos reconcilian con nada, porque no hay nada con lo cual reconciliarse, nos permiten quedarnos ahi, "resistiendo" serfa una palabra excesiva, nos permiten simplemente quedarnos ahi, en la quietud, no de quien reza, sino de quien escucha frente a la muerte que avanza, lentamente.

Lo que permanece, entonces: la upequeña mano». La pequeña mano es lo tenaz, pese a todo, la única eficiencia posible de nuestra fragilidad. ¿Como es esto? En cada rincón de la vida nos topamos con la tentación de la impotencia, el miedo de ser aplastado por algún poder y no saber ya qué hacer, $y$ no tener qué enfrentarle. Razones hay de sobra, y a cada paso, para sucumbir en tal tentación (incluso sin las ostentosas carencias enumeradas en el poema "Chopin"). Una manera de reaccionar es ceder a la tentación de la impotencia: nos escondemos; frente a cualquier arco de triunfo, uno busca reducirse, hasta desaparecer. Poco a poco, pues, ese cada vez más desesperado agarrarse a la consigna de empequeñecerse, de disminuirse hasta lo invisible, $\mathrm{y}$ creer con el señor $\mathrm{K}$. - iy con Kafka? - que, con ello, se deja pasar de largo al poder, que así, el poder, no irritado, se olvidará de nosotros para siempre, cuando, en realidad... nos estamos suicidando.

Sin embargo, hay también otra manera de responder a la casi inevitable tentación de la impotencia, aunque una manera infinitamente más ardua y más compleja: implica concentrarse en la milagrosa eficiencia de lo pequeño, pero genuino, ir haciendo bien pequeñas cosas, nada más que pequeñas cosas y en ningún momento desaparecer del todo, aceptando aquí y allá algunas furias que nos empujan. Como diría Fabio Morábito, ir con "lenta furia» y, de pronto, la vuelta de tuerca, lo pe- queño como la fuerza, como lo que da fuerza para seguir dando un paso, el siguiente paso, nada más que el siguiente paso, que ya es suficiente para si, sf... sobrevivir. $Y$, sobre todo, no alvidarse ni olvidar que, para decirlo con una paradoja, en la vida no hay otro perpetuum mobile que los procesos precarios. Sin embargo... ino me he alejado en exceso de la «marea textual" del poema?, ¿no estoy ya en medio de un itinerario sin fin?

Regreso, una vez más, a nuestra «reflexión retórica", luego, también, a las vagas palabras de Fierro y a las precisas palabras de Benn.

En relación con ambos postulados es tiempo ya de pensar su diferencia. El primer postulado, el postulado de la exhibición de las palabras es, claramente, un postulado técnico, un medio para lograr el fin que articula el segundo postulado o postulado del carácter definitivamente otro de la poesta: un poema es un empujón de palabras y cada lector hace lo que puede si ha sido empujado, un empujón de palabras, pues, como medio de que el poema logre apartarse, y apartarnos, del resto de los discursos y las prácticas y, con ello, provoque, nos provoque, desatando, asi, imaginación centrifuga. Pero, insisto, ¿que se busca con tales maniobras y propósitos, y para qué?

Se introdujo la operación del wapartarse provocandon de un modo muy general: un poema pone entre paréntesis la distraida confianza en las otras prácticas y discursos, incita a su subversión, se rie o los elogia..., en cualquier caso, elimina la conveniente niebla o velo de sobreentendido en que es habitual que se encuentren y que, felizmente para nuestros haceres, les quita, por así decirlo, sus perfiles afilados $y$, por ello, cortantes, su intensidad abrumadora e irruptiva. ¿Como es esto?

Si, por ejemplo, se lee una noticia 
informativa en un periódico, el lector va con relativa confianza directamente a sus contenidos. Sin embargo, imagínese que se destruye esa confianza; supongamos que alguien repasa una y otra vez el texto de la noticia con esa intensidad discontinuadora de quien lee poemas, atendiendo minuciosamente lo que se dice y cómo se lo dice, y, de esta manera apartándose del circuito de la comunicacion, y desplegando la imaginación en varias direcciones; ese lector le estaría otorgando a su lectura una fuerza fuera de lugar, que incluso es probable que acabe confundiendola. Simplificando: tal lector estaría convirtiendo a la tranquila noticia informativa en un texto que aparta, y provoca imaginación apasionada. Pero, vuelvo a insistir, ¿para qué ese terco apartarse y provocar obsesivamente imaginación centrífuga?

Por lo pronto, ya en la comunicación, es muy díficil no creer, o en gran medida no creer que nuestros modos de hacer, que nuestros modos de pensar -que los modos "normales", para nosotros, de hacer y pensar-son los únicos modos de hacer, de pensar. En este sentido, hablar de esa espesa niebla, esa confianza, el velo de sobreentendido que cubre cualquier hacer $o$ pensar, es otra manera de referimos al hecho de que los prejuicios se enraizan muy hondo y muy fuerte. La lectura de un poema en tanto poema, al procurar con frecuencia levantar ese velo nebli- noso de sobreentendidos, al devolvernos contingencia e imaginación, nos devuelve, o más bien, nos descubre opciones.

Por ejemplo, al leer los poemas eLa entonces música" $y$ "Chopin", tan diferentes, por otra parte, sin duda somos "tocados» por... el uso y mención de ciertas palabras - primer postulado-, y con ello, se provoca... y convoca nuestra imaginacion centrífuga -segundo postulado- a apartarnos $y$ atender experiencias empeñosamente dejadas de lado: ambos poemas nos empujan a imaginar-recordar aquello sobre lo cual nada se quiere saber. No obstante, no se trata necesariamente de ningún malabarismo con el deseo: esas otras experiencias no se encuentran más allá de esta vida, o a su lado, sino en su interior, en medio de sus pasos, «trágicamente» sosteniéndonos. La pequeña palabra y la pequeña mano: la pequeña palabra que explica y me explica, que narra y me narra, la pequeña palabra que, una $y$ otra vez, afirma $y$, así, me afirma, y la pequeña mano sobre el hombro, la pequeña mano que trabaja hasta que ya no puede más y cae exhausta, la pequeña mano que acaricia mi rostro, la que toca ciertos "preludios", prologos a lo que todavía no es: pequeña mano y pequeña palabra que pronto mueren, pero que en su precario y a veces maravilloso y a veces horrible transcurrir, hacen nuestras vidas. 